Open Access

\title{
Development of an indirect ELISA, blocking ELISA, fluorescent microsphere immunoassay and fluorescent focus neutralization assay for serologic evaluation of exposure to North American strains of Porcine Epidemic Diarrhea Virus
}

Faten Okda ${ }^{1,2}$, Xiaodong Liu', Aaron Singrey ${ }^{1}$, Travis Clement ${ }^{1}$, Julie Nelson' ${ }^{1}$ Jane Christopher-Hennings ${ }^{1}$, Eric A. Nelson ${ }^{1}$ and Steven Lawson ${ }^{1 *}$

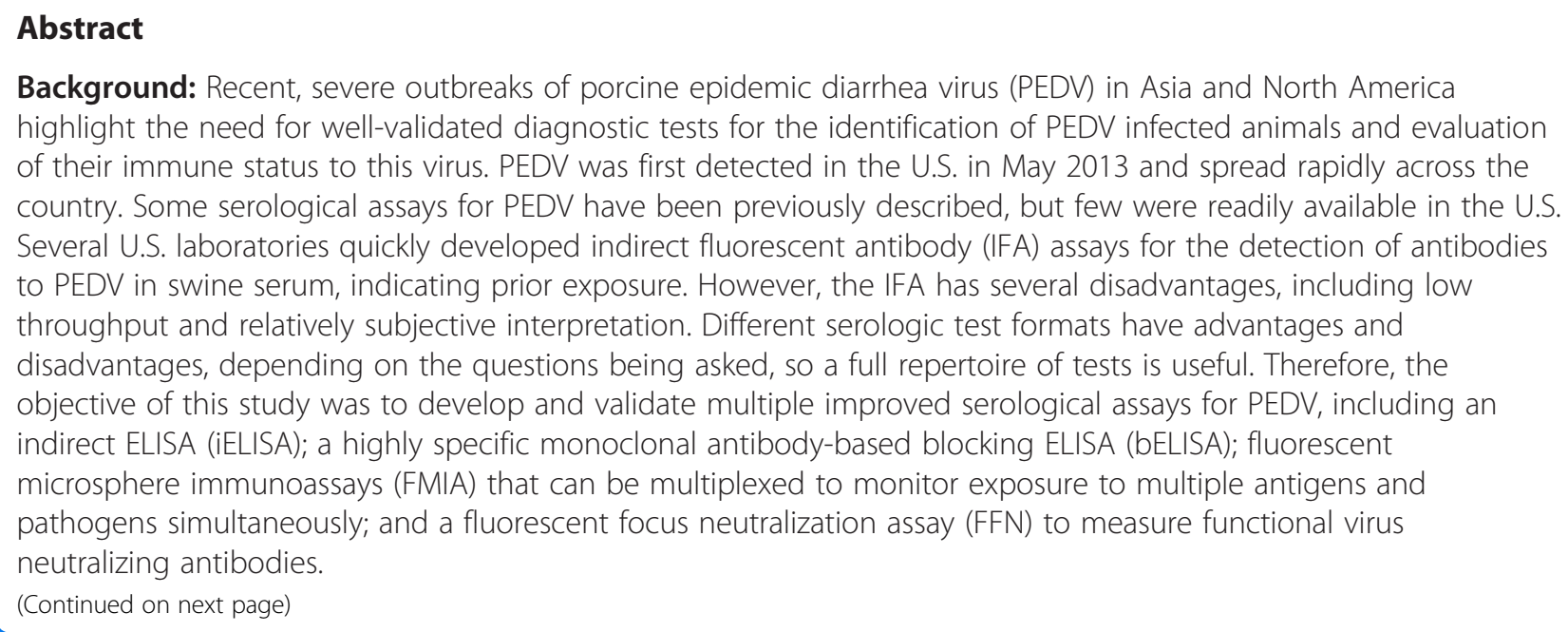

\footnotetext{
* Correspondence: steven.lawson@sdstate.edu

${ }^{1}$ Veterinary \& Biomedical Sciences Department, South Dakota State

University, Brookings, SD, USA

Full list of author information is available at the end of the article
} 
(Continued from previous page)

Results: A recombinant North American nucleoprotein (NP) based iELISA was developed and validated along with a bELISA using newly developed PEDV-NP specific biotinylated monoclonal antibodies (mAbs) and an FMIA using magnetic beads coupled with expressed NA PEDV-NP. Receiver operating characteristic (ROC) analysis was performed using swine serum samples (iELISA $n=1486$, bELISA $n=1186$, FMIA $n=1420$ ). The ROC analysis for the FMIA showed estimated sensitivity and specificity of 98.2 and $99.2 \%$, respectively. The iELISA and bELISA showed a sensitivity and specificity of 97.9 and $97.6 \%$; and 98.2 and $98.9 \%$, respectively. Inter-rater (kappa) agreement was calculated to be 0.941 between IELISA and IFA, 0.945 between bELISA and IFA and 0.932 between FMIA and IFA. Similar comparative kappa values were observed between the iELISA, bELISA and FMIA, which demonstrated a significant level of testing agreement among the three assays. No cross-reactivity with the closely related coronaviruses, transmissible gastroenteritis virus (TGEV) or porcine respiratory coronavirus (PRCV) was noted with these assays. All three assays detected seroconversion of naïve animals within 6-9 days post exposure. The FFN assay allows relative quantitation of functional neutralizing antibodies in serum, milk or colostrum samples.

Conclusion: Well-validated iELISA, bELISA and FMIA assays for the detection of PEDV antibodies were developed and showed good correlation with IFA and each other. Each assay format has advantages that dictate how they will be used in the field. Newly developed mAbs to the PEDV-NP were used in the bELISA and for expediting FFN testing in the detection and quantitation of neutralizing antibodies. In addition, these PEDV mAbs are useful for immunohistochemistry, fluorescent antibody staining and other antigen-based tests. Measurement of neutralizing antibody responses using the FFN assay may provide a valuable tool for assessment of vaccine candidates or protective immunity.

Keywords: Porcine epidemic diarrhea virus (PEDV), Serology, ELISA, Fluorescent microsphere immunoassay (FMIA), Fluorescent Focus Neutralization (FFN)

\section{Background}

Porcine epidemic diarrhea virus (PEDV) was first described in Europe in the 1970s with more recent and severe outbreaks in Asia [1, 2]. The virus was identified in the United States in May 2013, causing severe diarrhea and vomiting in pigs across age groups, with high mortality of up to 90 $-95 \%$ in suckling pigs [3]. PEDV is an enveloped, single stranded RNA virus belonging to the Coronaviridae family. The coronaviruses taxonomically form a subfamily (Coronavirinae) within the order Nidovirales. Recently, the International Committee on Taxonomy of Viruses (ICTV) recognized four genera within the Coronavirinae subfamily: Alphacoronavirus, Betacoronavirus, Gammacoronavirus, and Deltacoronavirus [4]. PEDV belongs to the genus Alphacoronavirus along with other swine viruses including transmissible gastroenteritis virus (TGEV) and porcine respiratory coronavirus (PRCV).

The genome is composed of a large $\sim 28 \mathrm{~Kb}$ molecule consisting of a $5^{\prime}$ untranslated region (UTR), a 3' UTR, and at least seven open reading frames (ORFs) encoding three nonstructural proteins: ORF1ab (pp1a and pp1ab) and ORF3, an accessory protein. The four major structural proteins of the mature virion include the spike (S) glycoprotein (Mr 150-220 kDa), the nucleoprotein (NP) $(\mathrm{Mr} 45-57 \mathrm{kDa})$ that is associated with the positive stranded RNA providing integral support for its helical structure, the glycosylated membrane protein $(\mathrm{M})(\mathrm{Mr}$
$20-30 \mathrm{kDa})$, and the glycosylated envelope protein $(\mathrm{E})$ ( $\mathrm{Mr} 7 \mathrm{kDa})$ [5-7].

Coronaviruses are taxonomically assigned to different genera based on their rooted phylogeny and calculated evolutionary distance for seven highly conserved genomic domains within ORF 1ab [8]. The genetic diversity of coronaviruses may be due to their high frequency of recombination [9]. The heterogeneity among coronavirus subfamilies is well documented [7], and the factors that contribute to PEDV's ability to gain or lose parts of its transcriptome are believed to have contributed to quasispecies with novel traits that are able to adapt to new hosts, ecological niches and zoonotic events. The exact origin of PEDV in North America is not entirely clear, but there is evidence of genetic similarities to Chinese PEDV strains [10].

Recently, a novel NA PEDV recombinant strain was identified (S INDEL) containing both insertions and deletions within the N-terminal domain of the ORF 3 and S1 genes. Specifically, sequence alignment indicated spike gene nucleotide deletions at positions 164-169 that correspond to amino acid deletions at positions 55 and 56 in addition to substitutions at positions 23 (I), $31(\mathrm{H}), 57(\mathrm{~K})$, and $59(\mathrm{E})$ as compared to the CV777strain $[10,11]$.

The relatedness of several PEDV strains circulating in China was evaluated by Li et al. [5] using phylogenic analysis of the NP gene and no insertions or deletions 
were noted. Sequence comparison with other European and Korean PEDV strains obtained from GenBank indicated that the NP genes were highly conserved (94.7-97.7 \%) even though these strains originated from different geographic regions [5]. In addition to being highly conserved among PEDV variants, the NP is the most abundant viral protein expressed in PEDV infected cells $[12,13]$. In contrast, the spike protein is presented on the viral surface and subject to various host immune pressures, which predisposes it to a greater range of genetic heterogeneity including insertions and deletions. Because the NP protein is highly abundant in virus infected cells, it provides an attractive target for the development of antigen-based serological assays. Taken together, this evidence provided rationale for using it as our antigen of choice for the iELISA, bELISA and FMIA.

In response to the recent outbreaks of highly virulent PEDV in North America (NA), PCR assays were quickly developed to detect the presence of PEDV RNA in intestine or fecal material. These assays provide an important tool in control of the virus; however, well-validated, high-throughput assays to detect antibodies following infection would provide additional valuable diagnostic tools for the swine industry. The ability to detect and evaluate antibody responses using serologic tests is important in efforts to answer basic production related questions. These questions may include whether a production site is naïve or has historically experienced a PEDV exposure, even though a producer has not seen obvious clinical signs; the level of immune response sows may have in relation to vaccination, initial wildtype virus infection or intentional feedback exposure; and whether sow immunity is inadequate when clinical infection occurs in individual litters after initial PEDV exposure in a herd.

One of the most pressing issues of PEDV disease is maintaining herd site biosecurity through exclusion measures to prevent viral entrance into swine units. However, PEDV infection may not always be obvious in finishing pigs so the widespread transport of these animals may represent additional risks. Thus, sensitive serological tests provide a valuable tool in the detection of recent infection to avoid the introduction of these animals into naïve herds.

Since PEDV was widespread in Europe in the 1970s and 1990s and more recently in Asia, various serologic tests have been developed and subjected to varying degrees of validation [14-20]. However, few assays have been developed using antigens associated with contemporary strains currently circulating across NA. The need to develop more sensitive serological assays has become paramount in order to address questions regarding PEDV infections and epidemiological transmission patterns, as well as to analyze disease progression.
Currently, serum virus neutralization (SVN) tests are the most widely employed serological assays used to detect PEDV antibodies. It is a test that is highly specific and useful for screening of antibody titer post vaccination $[1,16]$. However, the test is expensive and labor intensive, requiring manual reading and interpretation of virus induced cytopathic effect (CPE) endpoints. Moreover, serum cytotoxicity can be mistaken for viral $\mathrm{CPE}$, giving rise to false interpretations at lower serum dilutions.

Several laboratories have generated in-house indirect ELISAs using either virus derived antigen or recombinant structural proteins. Early indirect ELISAs were developed using Vero cell derived, whole virus preparations [15, 21] or Vero cell expressed viral proteins [16]. These methods may be problematic because serum from animals vaccinated with cell culture derived PEDV may cross-react with cellular components of ELISA antigen, causing low specificity and high background. Other groups have used recombinantly expressed, purified, structural $\mathrm{S}$ and NP proteins for iELISA serodiagnosis, but because low numbers of experimentally derived samples were used to evaluate the performance of the assay, full validation of the diagnostic sensitivities and specificities could not be assessed [19, 20].

Both the iELISA and bELISA formats have proven useful for the serodiagnosis of experimental and natural infections. Blocking or competitive ELISAs have been shown to be especially useful where a higher level of specificity is required. The increased specificity has been shown to be dependent on both the isotype and on the target specificity of the monoclonal or polyclonal antibodies [6, 17, 22]. Various laboratories have developed sensitive blocking ELISAs, and Carvajal et al. [17] demonstrated their bELISA was able to detect an antibody response 3 to 5 days earlier than IFA, which suggested higher sensitivity of the bELISA. In addition, the bELISA is valuable as a confirmatory test where unexpected positive results appear in presumably negative herds.

The fluorescent microsphere immunoassay is based on fluidic, particle array technology (Luminex Corp., Austin, TX) and has become increasingly standardized and accepted in applications involving the serologic diagnosis of autoimmune and animal infectious diseases [23, 24]. There are distinct advantages of the FMIA over the ELISA, which include higher sensitivity, higher sample throughput analysis, and the ability to multiplex and monitor exposure to multiple pathogens simultaneously in a single sample. In addition, multiple bead sets in the FMIA could be added to a standardized assay against newer virus subtypes that continue to emerge in the field or to assess antigenic/phylogenetic differences between genera of coronaviruses.

In this study, we report the adaptation of a recombinant, highly purified, NA PEDV-NP antigen to the 
development of iELISA, bELISA and FMIA platforms for the detection of PEDV antibodies in serum. These assays provide high throughput serological tests designed to address PEDV disease diagnostics. They were fully validated using a large number of serum samples of known status, and validation of the tests was detailed using methods for the validation of serological assays for the diagnosis of infectious diseases previously described by Jacobson for the Office International des Epizooties [25]. In addition, a fluorescent focus neutralization (FFN) assay was developed for the rapid evaluation of neutralizing antibody responses.

\section{Methods}

\section{Ethics Statement}

Procedures involving animals were approved by the South Dakota State University Institutional Animal Care and Use Committee (IACUC) under approval numbers 13-054A and 04-A034. Time course swine serum samples provided by Kansas State University were part of a separate PEDV challenge study conducted at the Biosecurity Research Institute approved by the Kansas State University Institutional Animal Care and Use Committee. All other serum samples were obtained as routine diagnostic sample submissions at the South Dakota ADRDL.

\section{Animal samples for assay validation and time-course sero- logical evaluation}

For time course studies, serum samples from experimentally infected animals were obtained courtesy of Dr. Richard Hesse (Kansas State University Veterinary Diagnostic Laboratory, National Pork Board Grant \#13-228). Thirty-three PEDV naïve 3-week-old feeder pigs were obtained from a private, high-health status swine production farm. . Of the 33 pigs, 23 were inoculated with PEDV at 4 weeks of age via intranasal and oral routes with a pool of gut derived intestinal contents that had been used as "feedback" inocula for controlled exposure of a sow herd. Serum was collected prior to challenge and at days $0,6,9,14,21,28,35$ and 43 days post-infection (DPI). Multiple aliquots of all samples collected were shared with requesting laboratories to expand diagnostic testing and vaccine development capabilities.

To accurately assess the diagnostic sensitivity and specificity of the assays, samples of known serostatus for PEDV were used. This included sera from multiple animal populations including experimentally infected animals and serum samples from animals with known historical exposure to PEDV that were submitted to the South Dakota Animal Disease Research and Diagnostic Laboratory (ADRDL). PEDV negative sample sets included samples from PEDV negative control pigs used in experimental studies and selected high biosecurity herds with no history of PEDV. In addition, archived serum samples collected prior to the emergence of PEDV in the U.S., including samples testing positive for the related swine coronaviruses TGEV and PRCV $(n=>50)$, were used. The exact number of positive and negative sera used for sensitivity and specificity calculations per assay with statistical testing agreement calculations based on serum numbers is listed in Table 1. The majority of these sera were identical among assays, but limited serum volume did not allow for use of all sera samples among all assays.

\section{Antigen production, expression of recombinant PEDV-NP protein}

The development and validation of the iELISA and bELISA made use of a recombinantly expressed full length NA PEDV-NP. The NP open reading frame (ORF) of PEDV was amplified from RNA extracted directly from intestinal contents by RT-PCR from a case submitted to the South Dakota ADRDL. It was subsequently directionally cloned into the E. coli, pET 28a(+), plasmid expression vector (Novagen, Madison, WI), then transformed into BL21-Codon Plus (DE3)-RP competent cells (Stratagene, La Jolla, CA) for protein expression. Primers used for the amplification of the full length (1323 bp) nucleoprotein were: PEDV-NP-fwd (5'-CG CGGATCCATGGCTTCTGTCAGTTTTCAG-3'); PED V-NP-rev (5' - CACACTCGAGATTTCCTGTGTCGAA GATCTC-3'). Next, $20 \mu \mathrm{l}$ of transformed cells were plated onto Luria-Bertani agar plates containing $50 \mu \mathrm{g}$ of kanamycin $/ \mathrm{ml}$ and incubated overnight. The following morning, colonies from the agar plates were added to $1 \mathrm{~L}$ of pre-warmed $2 \mathrm{X}$ yeast extract tryptone (YT) culture medium containing $50 \mu \mathrm{g}$ kanamycin/ml and allowed to grow to an $\mathrm{OD}_{600}$ of 0.5 at $37^{\circ} \mathrm{C}$. PEDV-NP expression was induced using isopropyl $\beta$-D-1-thiogalactopyranoside (IPTG) at a final concentration of $1.0 \mathrm{mM}$ to induce transcription of the Lac operon, and the $E$. coli was allowed to incubate for an additional $8 \mathrm{~h}$

Table 1 Evaluation of statistical agreement among serological testing platforms. Multiple comparison, inter-rater agreement (kappa association) was calculated among all four tests. Kappa values shown represent a statistical measure of test agreement and were calculated using MedCalc version 11.1.1.0

\begin{tabular}{lllll}
\hline & FMIA & bELISA & Indirect ELISA & IFA \\
\hline IFA & 0.932 & 0.945 & 0.941 & 1 \\
iELISA & 0.919 & 0.923 & 1 & 0.941 \\
bELISA & 0.941 & 1 & 0.923 & 0.945 \\
FMIA & 1 & 0.941 & 0.919 & 0.932 \\
Number Positive Serum Samples & 158 & 158 & 158 & 158 \\
Number Negative Serum Samples & 361 & 361 & 361 & 361 \\
Total Serum Samples Tested & 519 & 519 & 519 & 519 \\
\hline
\end{tabular}


at $37^{\circ} \mathrm{C}$ with shaking at $200 \mathrm{RPM}$. The agar was strained out and bacteria pelleted by centrifugation at 12,000 $\mathrm{g}$ for $10 \mathrm{~min}$ at $4{ }^{\circ} \mathrm{C}$. The pellet was resuspended in $40 \mathrm{ml}$ of lysis buffer solution (B-PER, Pierce, Rockford, IL), incubated for $15 \mathrm{~min}$ at $20-22{ }^{\circ} \mathrm{C}$, then centrifuged at $12,000 \mathrm{~g}$ to separate the soluble from insoluble proteins. The PEDV-NP recombinant protein was expressed as insoluble periplasmic inclusion bodies. The resulting 441 amino acid recombinant protein was denatured using $8 \mathrm{M}$ urea, subsequently purified three times using nickel-NTA affinity column chromatography and refolded back to its native conformational state. Individual affinity column elutions were collected, pooled and confirmed by SDSPAGE, then aliquoted/frozen at $-80{ }^{\circ} \mathrm{C}$. The correct nucleotide sequence was confirmed by sequence and restriction endonuclease analysis. The average protein yield produced by the pET28a-PEDV-NP plasmid construct was calculated to be $11 \mathrm{mg}$ PEDV-NP per liter of 2XYT under the aforementioned conditions. The recombinant protein was detected and a predicted molecular weight of $51 \mathrm{kDa}$ was confirmed via Western Blotting using convalescent sera, a 6X histidinespecific mAb (Novagen, Madison, WI) and a PEDV-NP specific mAb (Figs. 1 and 2).

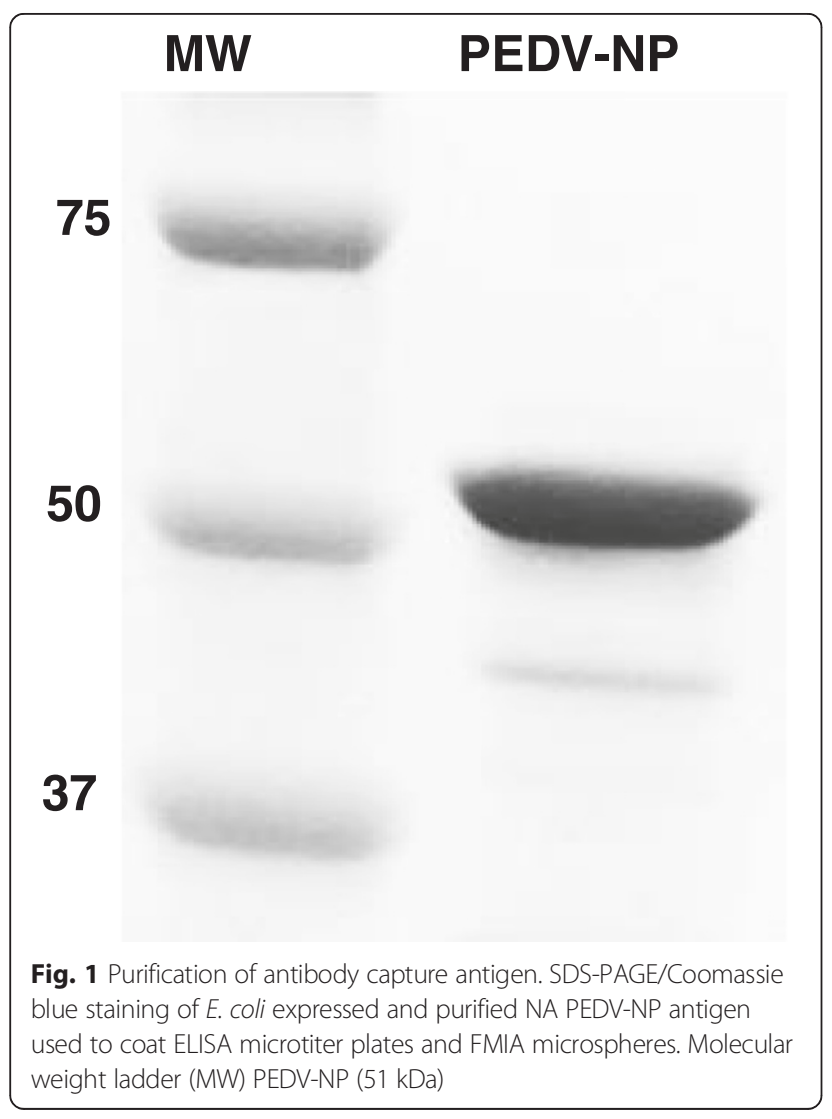

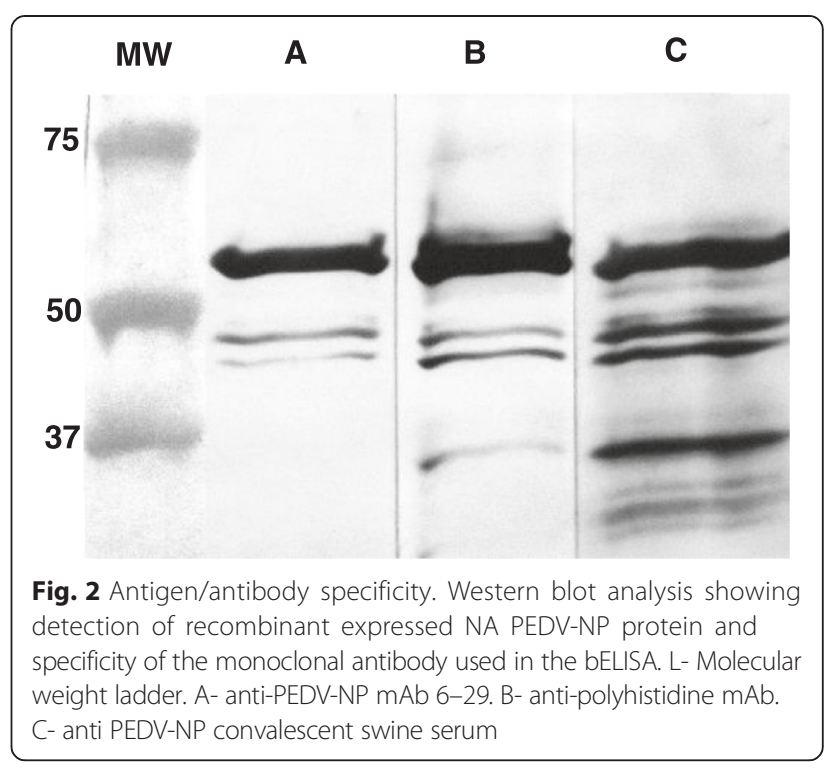

\section{$m A b$ production and biotinylation}

Two separate mAbs were developed in our laboratory (SD6-29 and SD17-103) that recognize both the native conformation of the PEDV-NP and the full length, linear, recombinant protein used in all antibody capture assays. Hybridomas were produced as previously described $[26,27]$. Immunoglobulin isotyping of the resulting mAbs was performed using a commercial lateral flow assay (Serotec, Raleigh, NC). Subsequently, mouse ascites fluid was produced in pristane-primed mice, and the antibodies were purified and biotinylated for use as the detection moiety for the bELISA [23]. The conjugated antibody solution was quantified via the Lowry protein method, and carrier BSA was added to a final concentration of $10 \mathrm{mg} / \mathrm{ml}$, then aliquoted and stored at $-20{ }^{\circ} \mathrm{C}$.

\section{IFA}

Vero-76 cells (ATCC CRL-1587) were cultured with $\mathrm{MEM}+10 \% \mathrm{FBS}$ for $48-72 \mathrm{~h}$ until fully confluent in 96-well plates, then washed twice with MEM. Subsequently, alternating rows of 96-well plates were inoculated with the cell culture adapted PEDV NVSL-CO strain of PEDV (PEDV USA/Colorado/2013, GenBank accession number KF272920) at a multiplicity of infection (MOI) of 0.05 with MEM supplemented with $1.5 \mu \mathrm{g} / \mathrm{ml}$ trypsin (TPCK treated, bovine derived (Sigma, St. Louis, MO)). After incubation at $37{ }^{\circ} \mathrm{C}$ for $20-24 \mathrm{~h}$, monolayers were fixed with $80 \%$ acetone for $20 \mathrm{~min}$. Serum samples were initially serially diluted from 1:40 to 1:320 with PBS in duplicate wells, and $100 \mu \mathrm{ls}$ of the diluted serum were added to each well. The plates were incubated at $37{ }^{\circ} \mathrm{C}$ for $1 \mathrm{~h}$ and then rinsed $3 \mathrm{X}$ with PBS. Next, fluorescein isothiocyanate (FITC)-conjugated goat anti-swine IgG (KPL, West Chester, PA) was prepared at a dilution of 1:15 with PBS and $50 \mu$ l added to each well. 
After $1 \mathrm{~h}$ of incubation at $37{ }^{\circ} \mathrm{C}$, plates were rinsed $3 \mathrm{X}$ with PBS and examined using fluorescent microscopy. For each individual test, each PEDV infected well was compared to its respective uninfected partner well, and a positive sample was indicated if a PEDV specific fluorescent signal was observed at a serum dilution of 1:40 or greater. All samples were tested in duplicate, and the antibody titer was expressed as the mean of all replicates.

\section{iELISA}

The serological PEDV-NP indirect ELISA was performed by coating alternate wells of Immulon 1B, 96-well, microtiter plates (Thermo Labsystems, Franklin, MA) with $250 \mathrm{ng} /$ well of purified, recombinantly expressed PEDVNP antigen. The optimal dilution of the recombinant protein and secondary detection antibody was determined by a checkerboard titration that gave the highest signal to noise ratio. In addition, a single lot of pooled convalescent serum from PEDV infected pigs was used to generate quality control standards that gave high and low optical density (high $\mathrm{OD}=2.0$ to 2.5 ; low $\mathrm{OD}=0.5$ to 1.0 ; and negative $\mathrm{OD}<0.2$ ). PEDV-NP recombinant protein was diluted to $2.5 \mu \mathrm{g} / \mathrm{ml}$ in $15 \mathrm{mM}$ sodium carbonate-35 mM sodium bicarbonate- antigen coating buffer (ACB) $\mathrm{pH}$ 9.6. Odd-numbered columns were coated with $100 \mu \mathrm{l}$ of ACB plus antigen, while the evennumbered columns were coated with $\mathrm{ACB}$ without antigen, serving as background control. The plates were incubated for one hour at $37{ }^{\circ} \mathrm{C}$, then washed $3 \mathrm{X}$ with PBS plus $0.05 \%$ tween $_{20}$ (PBST). Each well was then blocked with $200 \mu \mathrm{l}$ of sample milk diluent (PBST plus $5 \%$ nonfat dry milk, (SMD)) and allowed to incubate overnight at $4{ }^{\circ} \mathrm{C}$. The following day, the plates were washed 3X with $300 \mu \mathrm{l}$ of PBST. Test and control sera were diluted 1/50 in SMD, mixed, and $100 \mu$ of the solution was added to each well. The plates were incubated for $1 \mathrm{~h}$ at $20-22{ }^{\circ} \mathrm{C}$. Next, $100 \mu \mathrm{l}$ of biotinylated, goat anti-swine detection antibody (Bethyl Laboratories, TX) was added at a concentration of $200 \mathrm{ng} / \mathrm{ml}$ of PBST and allowed to incubate at $20-22{ }^{\circ} \mathrm{C}$ for $1 \mathrm{~h}$. The plate was washed 3X with $300 \mu \mathrm{l}$ of PBST, then $100 \mu \mathrm{l}$ of streptavidin-HRP conjugate (Pierce, Rockford, IL) was added and incubated for another hour at $20-22{ }^{\circ} \mathrm{C}$, then washed and developed with 3,3',5,5' - tetramethylbenzidine, peroxidase substrate (TMB) (Surmodics, Eden Prairie, MN). Color development progressed until the positive control attained a standard OD and was stopped using $2 \mathrm{~N} \mathrm{H}_{2} \mathrm{SO}_{4}$. Colorimetric development was quantified spectrophotometrically at $450 \mathrm{~nm}$ with a ELx800 microplate reader (BioTek Instruments Inc., Winooski, VT) controlled by XCheck software (Idexx Laboratories, Westbrook, ME). The raw data was normalized and transformed into an Excel spreadsheet. Sample to Positive $(\mathrm{S} / \mathrm{P})$ ratios were calculated using the following formula: $S / P=$ optical density $(\mathrm{OD})$ of sample - OD of buffer/OD of positive control - OD of buffer.

\section{bELISA}

The serological bELISA was performed using Immulon 1B, 96-well microtiter plates (Thermo Labsystems, Franklin, MA). Alternate wells of each plate were coated with $500 \mathrm{ng}$ per well of expressed PEDV-NP antigen. The optimal dilution of the recombinant protein and $\mathrm{mAb}$ antibody was determined by a checkerboard titration that gave the highest signal to noise ratio with an OD reading of approximately 2.0, in the absence of swine serum/competitor antibody. First, PEDV-NP recombinant protein was diluted to $2.5 \mu \mathrm{g} / \mathrm{ml}$ of $\mathrm{ACB}$. Odd-numbered columns were coated with $100 \mu \mathrm{l}$ of $\mathrm{ACB}$ plus antigen, while the even-numbered columns were coated with ACB without antigen serving as background control. The plates were incubated for $1 \mathrm{~h}$ at $37{ }^{\circ} \mathrm{C}$, washed 3 times with PBST, then placed at $4{ }^{\circ} \mathrm{C}$ overnight. The following day, each well was blocked with $300 \mu \mathrm{l}$ of SMD and incubated one hour at $37^{\circ} \mathrm{C}$. Plates were washed 3 times with PBST, and $100 \mu \mathrm{l}$ of test and control sera were diluted $1 / 3$ with PBST $+0.1 \%$ nonfat dry milk and added to each of the duplicate wells. Plates were incubated $1 \mathrm{~h}$ at $37{ }^{\circ} \mathrm{C}$. During sample incubation, PEDV-NP specific biotinylated, mAbs (SD6-29 and SD17-103) were adjusted to equal titers and mixed together in a 1:1 ratio. Next, $100 \mu \mathrm{l}$ of a 1:40,000 dilution of the antibody detection mixture was added to the microtiter plate containing the competitive swine antibody, then swirled and incubated for an additional $30 \mathrm{~min}$ at $37{ }^{\circ} \mathrm{C}$. The plates were washed 3 times, and $100 \mu \mathrm{l}$ of high sensitivity, streptavidin-horseradish peroxidase conjugate (Pierce, Rockford, IL) was added to all wells of the microtiter plate for $1 \mathrm{~h}$ at $37^{\circ} \mathrm{C}$.

Plates were washed 4 times with PBST, and $100 \mu \mathrm{l}$ of TMB was added to all wells and gently swirled. After approximately $15 \mathrm{~min}$, color development progressed until the negative control attained a standard OD of approximately 2.0 and was subsequently stopped using $2 \mathrm{~N}$ $\mathrm{H}_{2} \mathrm{SO}_{4}$. Colorimetric development was quantified spectrophotometrically at $450 \mathrm{~nm}$ with an ELx800 microplate reader (BioTek Instruments Inc., Winooski, VT) controlled by XCheck software (Idexx Laboratories, Westbrook, ME). The raw data was normalized and transformed into a Excel spreadsheet, and the percent inhibition (PI) ratio was calculated using the following formula: $\mathrm{PI}=1-\{(\mathrm{OD}$ of sample - OD of buffer $) /(\mathrm{OD}$ of negative control - OD of buffer)\} X 100.

\section{Preparation of PEDV-NP coupled microspheres for the FMIA}

A two-step carbodiimide coupling procedure was used to couple NA PEDV-NP protein to Luminex ${ }^{\mathrm{Tm}}$ micro- $^{-}$ spheres. Briefly, the coupling of fluorescent microsphere 
was performed by washing $3.125 \times 10^{6}$ microspheres twice with $250 \mu \mathrm{l}$ activation buffer $\left(0.1 \mathrm{MNaH}_{2} \mathrm{PO}_{4}\right.$, pH6.2) and sonicating them for $60 \mathrm{~s}$ after each wash. Microspheres were activated for $20 \mathrm{~min}$ at $20-22{ }^{\circ} \mathrm{C}$ in $500 \mu \mathrm{l}$ activation buffer containing $2.5 \mathrm{mg} N$-hydroxysulfosuccinimide (sulfo-NHS) and $2.5 \mathrm{mg} N$-(3- dimethylaminopropyl)- $N$-ethylcarbodiimide (EDC) (Pierce Chemical, Rockford, IL). Activated microspheres were washed twice with PBS and sonicated. Coupling was initiated by the addition of $12.5 \mu \mathrm{g}$ of recombinant NA PEDV-NP protein, brought to a final volume of $500 \mu \mathrm{l}$ with PBS and incubated in the dark for $3 \mathrm{~h}$ at $20-22{ }^{\circ} \mathrm{C}$ with rotation. Coupled microspheres were washed once with $1 \mathrm{ml}$ of PBS plus $0.05 \% \mathrm{NaN}_{3}$ and $1.0 \%$ bovine serum albumin (PBS-NB). Next, the microspheres were blocked with $1 \mathrm{ml}$ of PBS-NB for $30 \mathrm{~min}$ to reduce nonspecific binding. Microspheres were then washed twice with PBS-NB and resuspended in PBS-NB to a final concentration of $2.0 \times 10^{6}$ antigen-coupled microspheres $/ \mathrm{ml}$.

\section{FMIA}

A 96-well hydrophilic membrane filter plate was blocked for 2 min with $150 \mu \mathrm{l}$ of PBS-NB, and then the liquid was aspirated via vacuum manifold. The plates were wetted with $20 \mu \mathrm{l}$ of PBS-NB buffer to prevent drying. Next, $50 \mu \mathrm{l}$ of serum (diluted 1:50 in PBS-NB) was added to duplicate wells of the filter plate along with $50 \mu \mathrm{l}$ of PBS-NB containing $2.5 \times 10^{3}$ antigen-coupled microspheres. Since the microspheres and reporter moieties are light sensitive, all incubations were performed in the dark by sealing the plate with foil. Subsequently, the FMIA plate was incubated at $20-22{ }^{\circ} \mathrm{C}$ for $1 \mathrm{~h}$ on a plate shaker rotating at $600 \mathrm{rpm}$. The plate was washed 3 times with $200 \mu \mathrm{l}$ of PBST. Next, $50 \mu \mathrm{l}$ of anti-swine, biotinylated IgA (heavy \& light chain, diluted in PBS-NB; Bethyl Laboratories) or IgG-FC specific polyclonal antibodies (diluted 1:2,000 dilution in PBS-NB; Bethyl Laboratories) were added to the filter plate and incubated at $20-22{ }^{\circ} \mathrm{C}$ for $1 \mathrm{~h}$. NP IgM and IgG isotypespecific antibody levels were detected using PEDV-NP coated microspheres, but speciated by means of individual and separate IgM and IgG-specific secondary antibodies. Since validation was performed using serum, and because IgA is present in very low amounts, IgA specific secondary antibodies were not used at this step. After incubation with the secondary antibodies, $50 \mu \mathrm{l}$ of streptavidin phycoerythrin $(2.5 \mu \mathrm{g} / \mathrm{ml}$ in PBS-NB, Molecular Probes) was added to each well and incubated for $30 \mathrm{~min}$ at $20-22{ }^{\circ} \mathrm{C}$ with shaking. The supernatant was aspirated, and the plate was washed 3 times with PBST. Finally, the microspheres were resuspended in $125 \mu \mathrm{l}$ of PBST per well and transferred to a clear 96-well polystyrene optical plate. Coupled microspheres were analyzed through a dual-laser Bio-Rad Bio-Plex 200 instrument. The median fluorescent intensity (MFI) for 100 microspheres corresponding to each individual bead analyte was recorded for each well. All reported MFI measurements were normalized via $\mathrm{F}-\mathrm{F}_{0}$, where $\mathrm{F}_{0}$ was the background signal determined from the fluorescence measurement of a test sample in uncoated beads and $\mathrm{F}$ was the MFI for a serological test sample using antigencoated beads.

\section{Establishment of serological reference standards for ELISA and FMIA development}

Four serological reference serum sets were constructed as standards termed high, medium, low and negative to serve as internal quality control standards and to mathematically normalize individual samples for objective comparisons between testing platforms. The high-labeled standard was designed to generate an OD above 2.0 for the iELISA and bELISA and an MFI of approximately 25,000 for the FMIA. The high standard was used exclusively for the mathematical determination of the serological response ( $\mathrm{S} / \mathrm{P}$ ratio) of samples used for test validation. The medium standard generated a response of between 1.5 and 2.0 OD for the two ELISAs and approximately 10,000 MFI for the FMIA. The low standard was designed to deliver a signal slightly above threshold level for all 3 tests, and the negative serum generated an OD or MFI to a background level of less than 0.2 OD for the ELISAs and 600 MFI for the FMIA.

\section{Validation methods for the determination of diagnostic sensitivity, specificity, repeatability and threshold cutoff level}

To accurately assess the diagnostic sensitivity and specificity of the assays, samples of known serostatus for PEDV were used. This included sera from multiple animal populations including experimentally infected animals and serum samples submitted to the South Dakota ADRDL. PEDV negative sample sets included samples from selected high biosecurity herds with no history of PEDV and archived serum samples collected prior to the emergence of PEDV in the U.S., including samples testing positive for the related swine coronaviruses TGEV and PRCV. Known positive samples were collected from pigs that were naturally infected at least 3 weeks prior to collection and were previously positive by PCR. The negative-testing sample population (uninfected animals) consisted of maximally 980 PEDV negative serum samples, while the positive-testing (infected) population was composed of 516 serum samples. Receiver operating characteristic (ROC) analysis was calculated for each assay to assess diagnostic performance, which included determination of sensitivity, specificity and threshold cutoff using MedCalc version 11.1.1.0 (MedCalc software, Mariakerke, Belgium). 
The repeatability of each assay was assessed by running the same internal quality control serum standards in multiple replicates within the same run or between runs. For the iELISA and the bELISA, the intra-assay repeatability was calculated for 48 replicates on 3 separate plates, then repeated over a 3-day period for inter-assay repeatability assessment. The values for each assay were expressed as a mean, standard deviation and percent coefficient of variation (CV\%) for repeated measure.

\section{Measurement of statistical testing agreement}

Multiple comparison, inter-rater agreement (kappa measure of association) was calculated among all four tests (bELISA, iELISA, FMIA and IFA) using IBM, SPSS version 20 software (SPSS Inc., Chicago, IL). The sample cohort used was a well-characterized set of serum samples collected from "positive testing" experimentally infected pigs over time courtesy of Dr. Richard Hesse $(n=158)$ and from archived experimental control uninfected PEDV "negative testing" animals. The interpretation of kappa can be rated as follows: Kappa less than 0.0, "poor" agreement; between 0.0 and 0.20 , "slight" agreement; between 0.21 and 0.40, "fair" agreement; between 0.41 and 0.60, "moderate" agreement; between 0.61 and 0.80 , "substantial" agreement; and between 0.81 and 1.0, "almost perfect" agreement $[28,29]$.

\section{FFN}

A PEDV virus neutralization assay using a FFN format was developed for rapid detection of neutralizing antibodies produced in response to PEDV infection. The FFN was evaluated using serum samples or rennet treated milk and colostrum samples. Heat-inactivated samples were diluted in a 2-fold dilution series starting at 1:10 in MEM plus $1.5 \mu \mathrm{g} / \mathrm{ml}$ TPCK-treated trypsin in 96-well plates. An equal amount of cell culture adapted PEDV stock at a concentration of 100 foci forming units $/ 100 \mu \mathrm{l}$ was added to each well and plates incubated for $1 \mathrm{~h}$ at $37{ }^{\circ} \mathrm{C}$. The virus/sample mixture was then added to washed confluent monolayers of Vero-76 cells and incubated for $2 \mathrm{~h}$ at $37^{\circ} \mathrm{C}$. Plates were washed again with MEM/TPCK-trypsin medium and incubated 20-24 $\mathrm{h}$ to allow for replication of non-neutralized virus. Plates were then fixed with $80 \%$ acetone and stained with FITC conjugated mAb SD6-29 to allow visualization of infected cells. Endpoint neutralization titers were determined as the highest serum, milk or colostrum dilution resulting in a $90 \%$ or greater reduction in fluorescent foci relative to controls.

\section{Results}

Expression of recombinant PEDV-NP antigen

As shown in Fig. 1, the purity of the recombinant protein was assessed via SDS-PAGE and gave a band that migrated corresponding to the expected molecular mass of $51 \mathrm{kDa}$ upon staining with Coomassie brilliant blue R250. The protein yield of the IPTG induced $E$. coli culture was calculated to be approximately $11 \mathrm{mg}$ PEDV-NP/liter of 2XYT medium with a purity of greater than $95 \%$. The identity of the protein was further characterized by Western blot using convalescent swine serum, an anti-His $\mathrm{mAb}$ and an anti-PEDV-NP mAb (Fig. 2).

\section{Diagnostic sensitivity, specificity, repeatability and threshold cutoff level}

To optimize the serologic assays, various antigen and serum dilutions were used to determine optimum concentrations. All 3 tests were optimized in a checkerboard fashion to maximize signal-to-noise ratios. It was determined by antigen titration that the optimal coating of Luminex ${ }^{\mathrm{Tm}} /$ FMIA microspheres was achieved at a concentration of $12.5 \mu \mathrm{g}$ protein per $3.125 \times 10^{6}$ microspheres. Similarly, the optimum coating of both the iELISA and bELISA plates was achieved at a concentration of $250 \mathrm{ng} /$ well. In addition, to determine the optimum serum dilution for each of the testing platforms, a well-characterized PEDV "high" positive serum standard was serially diluted in a $\log _{2}$ titration against antigen coated microspheres (FMIA) or antigen coated ELISA wells at a fixed concentration. Figure 3 shows concentration-dependent OD or MFI signals of various serum standards. Overall, sample absorbance increased inversely proportional to the serum dilution. However, based upon the highest signalto-noise ratio, it was determined that the optimal serum dilution for the bELISA was $1 / 3$, while the iELISA and FMIA each demonstrated an optimum dilution of $1 / 50$ as indicated by arrows (Fig. 3).

ROC analysis to determine sensitivity, specificity and threshold cut-off levels was performed using large numbers of swine serum samples and demonstrated excellent agreement (>0.91 kappa scores) between assays with good intra and inter assay repeatability (Table 1). None of the known positive TGEV or PRCV samples tested was shown to cross-react.

The optimal cutoff values and corresponding sensitivity and specificity of each individual test are presented in Fig. 4. Specifically, ROC analysis for the iELISA and bELISA showed similar sensitivity and specificity of 97.9 and $97.6 \%$; and 98.2 and $98.9 \%$, respectively. The ROC analysis for the FMIA showed estimated sensitivity and specificity of 98.2 and $99.2 \%$, respectively. Although the FMIA showed an identical sensitivity as the bELISA, it demonstrated the highest degree of specificity of all three assays at $99.2 \%$. This observation was not surprising given that FMIA technology inherently imparts 

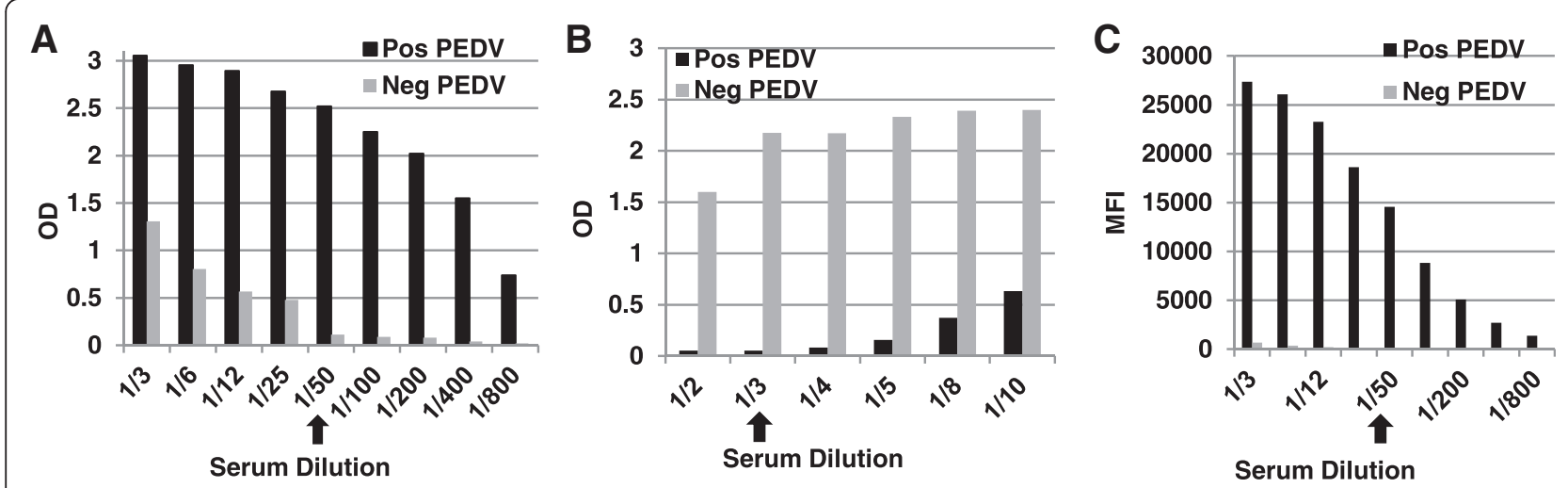

Fig. 3 Serum dilution optimization for both ELISA assays and FMIA. Reference serum standard was titrated 2-fold in antigen coated wells at a fixed concentration in order to gauge a maximum signal-to-noise ratio for each assay a iELISA, b bELISA, c FMIA. Arrows show the optimum dilution of swine serum from which the highest signal to noise ratio was achieved

greater sensitivity and a larger dynamic range than the ELISA platform [30].

In addition to determining cutoff values, sensitivities and specificities, multiple comparison tests were performed to calculate the degree of agreement among the ELISA, FMIA and IFA tests. Specifically, the Kappa test demonstrated all diagnostic platforms had kappa values greater than 0.91 , which demonstrates that all 4 tests are in "almost perfect" agreement with each other.

\section{Assessment of repeatability}

The iELISA and bELISA demonstrated slightly lower \%CVs than the FMIA with $3.7 \%, 6.8 \%, 10.7 \%$ intra-assay variability for bELISA, iELISA and FMIA respectively.
Inter-assay \%CVs were 5.0, 5.6 and $7.7 \%$ for the bELISA, iELISA and FMIA respectively. Nonetheless, all the CVs were $10.7 \%$ or less, which demonstrated that the tests were highly repeatable in a diagnostic application.

\section{Evaluation of a kinetic PEDV antibody response}

As shown in Fig. 5, a mean antibody response to PEDVNP could be detected as early as 9 DPI for both the iELISA and bELISA. The FMIA detected PEDV-NP antibodies slightly earlier at 6 DPI. All 3 tests detected the duration of antibody out to the 43 DPI time-point in this study but demonstrated a decline in detectable antibody after 21 DPI.

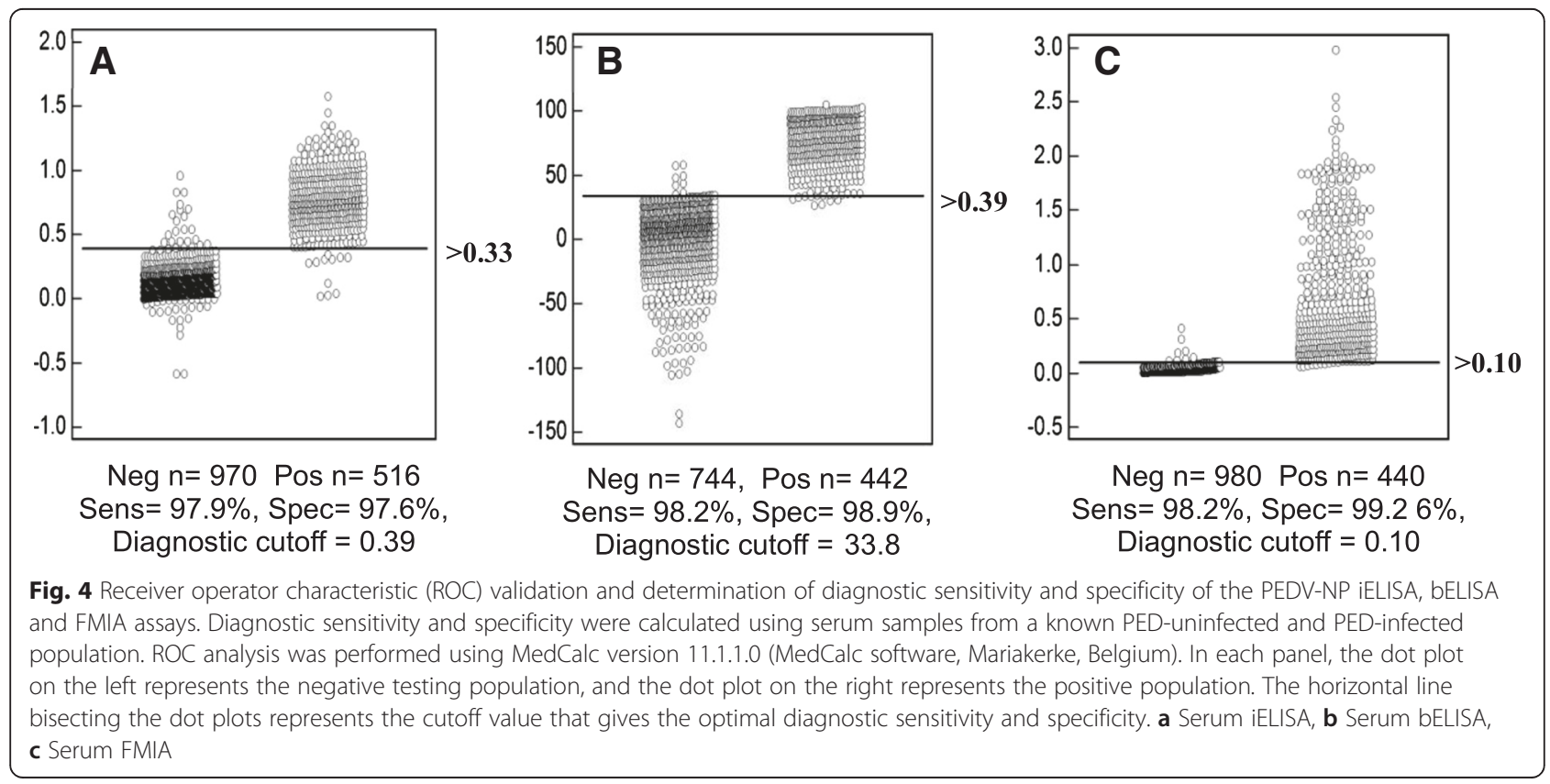



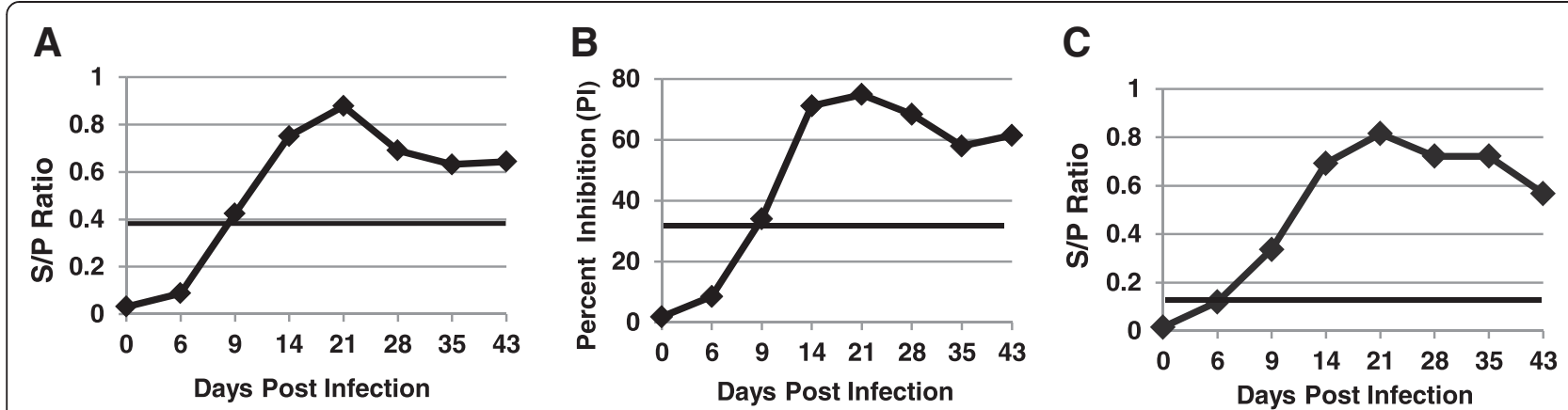

Fig. 5 Kinetic time course antibody evaluation. Antibody time course kinetics were calculated for each of the ELISAs and FMIA using serum samples from experimentally infected pigs collected at weekly intervals. The horizontal line indicates the diagnostic cutoff for each test. All three tests demonstrate similar kinetic curve responses via their calculated S/P values. a Antibody kinetic time course via iELISA, $\mathbf{b}$ Antibody kinetic time course via bELISA, c Antibody kinetic time course via FMIA

\section{Application of the FMIA to isotype PEDV-NP specific antibodies}

High levels of PEDV-NP specific IgM antibodies were observed at 7 DPI compared to IgG (Fig. 6). However, the IgM antibodies decreased to barely detectable levels by $20 \mathrm{DPI}$. IgG continued to increase linearly to $20 \mathrm{DPI}$. There is a concomitant appearance of neutralizing antibodies by 14 DPI.

\section{FFN}

The FFN assay was initially evaluated using sequential serum samples from experimentally inoculated piglets. Additional evaluation was conducted using 250 serum samples from known PEDV naïve herds and 250 samples from herds with documented PEDV exposure, collected at least 3 weeks after initial PCR diagnosis and whole herd feedback. Experimentally inoculated piglets demonstrated detectable seroconversion by 14 DPI (Fig. 6).

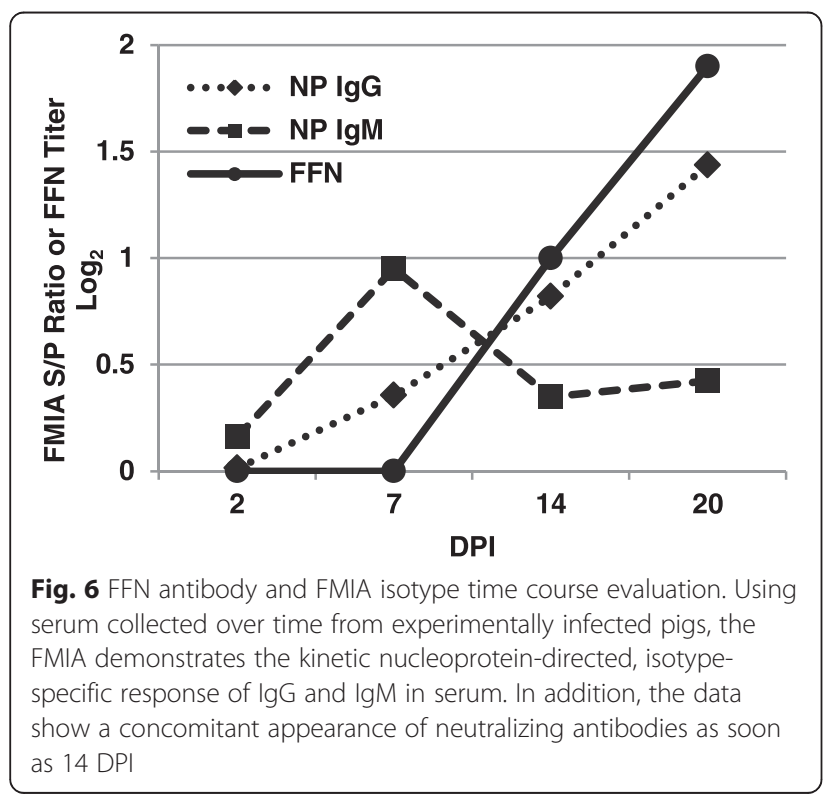

Essentially all samples from PEDV naïve animals had serum FFN endpoint titers of $<1: 20$ while most samples from the PEDV positive set had endpoint titers ranging from $1: 40$ to $1: 1280$ (data not shown). Further evaluation of the FFN included serum, milk and colostrum samples from 27 sows from a herd that had experienced an acute PEDV outbreak 6 to 7 weeks prior to farrowing. All animals were exposed to live virus twice within the first week of the outbreak, followed by one dose of Harrisvaccines Porcine Epidemic Diarrhea Vaccine, RNA (Harrisvaccines, Inc., Ames, IA) at 1 week pre-farrow. Serum and colostrum samples were tested at the time of farrowing, followed by serum and milk samples at 1 week and 2 weeks later. As shown in Fig. 7, mean colostrum titers were approximately 4-fold higher than serum titers at the time of farrowing. At later time-points, serum and milk titers were similar in magnitude, although substantial animal to animal variation was apparent.

\section{Discussion}

Overall, this repertoire of assays is useful for initial identification and efficient, high throughput quantitation of PEDV antibodies. We evaluated all three diagnostic platforms against a well characterized IFA and compared the individual serum IgM and IgG kinetic antibody responses in an FMIA to the appearance of neutralizing antibody as detected by the FFN assay. Each of the antibody-capture assays was validated using a large number of serum samples ( $\mathrm{n}>1100$ ) based upon the assay validation methods of Jacobson, which is supported by the Office International des Epizooties [25].

Since PEDV was first identified in the U.S. in May 2013, it has spread rapidly to at least 33 states (www.aasv.org) and has been reported in Mexico and Canada [31]. The virus causes severe gastroenteritis, destroying villus enterocytes in pigs of all ages, and is characterized by vomiting and diarrhea, leading to subsequent dehydration, high mortality rates and economic losses, particularly in 


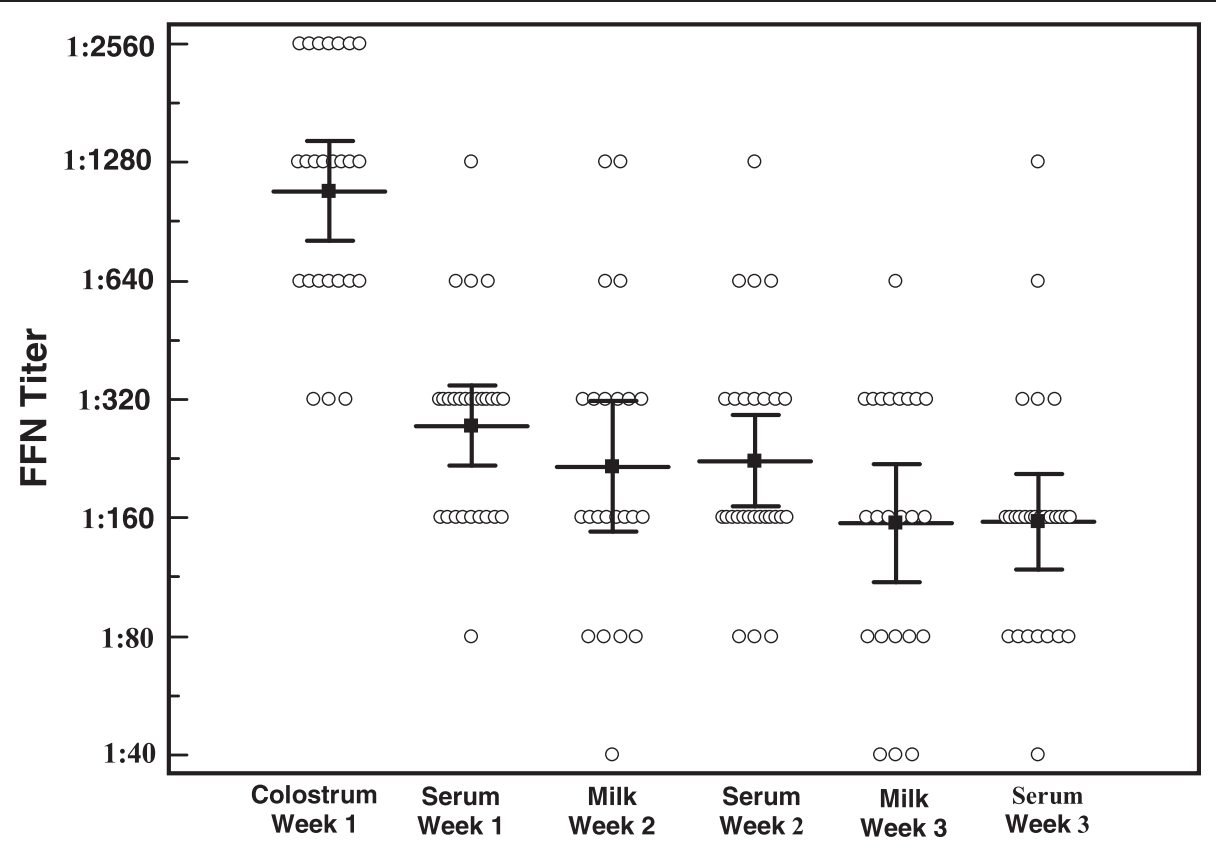

Fig. 7 Assessment of neutralizing antibody titers in different sample matrices following PEDV exposure. FFN titers were detected in various sample matrices including colostrum $(n=25)$, milk $(n=23)$ and serum $(n=27)$ collected at the time of farrowing and weekly for two weeks post-farrowing. Error bars indicate a $95 \%$ confident interval for mean titers indicated by horizontal lines

nursery piglets $[3,32]$. A variety of serological tests have been developed against PEDV, but they vary by antigen used and in the degree of validation. In addition, few have used North American NP based antigens or compared the array of serologic assays described here. In the current study, four tests (IFA, bELISA, iELISA, FMIA) showed strong correlation. Each has advantages, which dictate how they will be used in the field. In addition, newly developed NP mAbs were used in the bELISA and for expediting FFN testing in the detection of neutralizing antibodies.

In the development of the ELISAs and FMIA, the full length NA PEDV-NP gene was amplified directly from RNA extracted from PEDV-infected ileal tissue. Multiple sequence alignment analysis showed that the amplified NP gene shared a $100 \%$ nucleotide homology with that of the US Colorado strain isolated in 2013 (Genbank accession no. 13-019349). Several authors confirm that the NP carries multiple antigenic determinants that are conserved among the Coronaviridae [33, 34]. However, we performed one-way cross-reactivity testing using serum from TGEV and PRCV, and no antibody crossreactivity was detected within any of our assays. In addition to being highly conserved among various PEDV variants, the NP is the most abundant viral protein expressed in PEDV infected cells, making it an attractive target antigen [12, 13]. Using Western blotting experiments, we confirmed the finding of Hou et al. [19], in which they observed the level of expression of NP protein to be significantly higher than the level of the spike protein. Our study demonstrated that it is possible to achieve a protein yield of over $10 \mathrm{mg}$ per liter of culture with a purity of greater than $95 \%$.

The recombinant NP has previously been identified as a useful antigen in other ELISAs developed to detect antibodies in pigs located in China and Korea [19]. In a study by Hou et al. [19], the authors showed similar sensitivities and specificities of their iELISA compared to the iELISA described in this study. However, smaller numbers of known positive and negative samples were evaluated than in the current study.

Since no test has $100 \%$ specificity, a bELISA was developed that is useful for confirmatory testing due to its higher inherent specificity than the iELISA [35]. Blocking or competitive ELISAs have been constructed using monoclonal antibodies in PEDV serodiagnosis, and the specific methodology can affect the overall specificity and performance of the assay. Our method was based upon coating plates with highly purified NA PEDV-NP, then using a combination of two separate NA, antiPEDV-NP specific, biotinylated, monoclonal antibodies as the blocking/competitive detection step. This allows the capture of anti-NP antibodies at higher quantities and those with a greater range of antigen specificities. The analytical specificity of the NP-based bELISA is also dependent on the affinity of the mAbs used. The antibodies used in this study are directed against conserved epitopes on the nucleocapsid protein without any 
evidence of cross-reactivity to any other genera of Alphacoronavirus tested. A previous assessment of antigenic cross-reactivity was performed using these same mAbs against different strains of PEDV and TGEV [7]. In that study, the authors reported that both mAbs used in the bELISA reacted with all PEDV strains tested, namely the homologous US isolate $\mathrm{PC} 22 \mathrm{~A}$ and the heterologous strains S INDEL IOWA 106, S 197DEL PC177 and CV777, at similar titers. Neither of the PEDV-NP mAbs cross-reacted with either the TGEV Miller or Purdue strains. Not only were the bELISA mAbs tested for heterologous cross-reactivity, but all three diagnostic platforms were evaluated in their ability to capture antibody against TGEV and PRCV, and there was no cross-reactivity to either heterologous virus.

Serology testing with IFA, iELISA, bELISA or FMIA is useful in determining whether pigs were previously infected with PEDV, or if piglets have acquired antibodies through colostrum (eg. passive antibody transfer). However, tests that evaluate the functionality of the antibodies such as the FFN are needed to determine if the detected immune response could be helpful in providing protection to nursing piglets. Neutralizing antibodies may be protective through actions including blocking uptake of the virus into cells, preventing virus binding to receptors on cells, preventing uncoating of the virus genomes in endosomes and/or causing aggregation of virus particles. For enveloped viruses, such as PEDV, lysis of the virus may also occur when antiviral antibodies and serum complement disrupt the viral membrane. For these reasons, an FFN-based virus neutralization assay was developed to assess levels of PEDV neutralizing antibodies in serum, milk or colostrum samples. The FFN provides a more rapid determination of neutralizing antibody levels than is possible with traditional virus neutralization assays that rely on visualization of virusinduced CPE after three or more days incubation to allow for full development of PEDV CPE. The direct observation of fluorescent stained infected cells, or lack of stained infected cells in the case of virus neutralization, allows for simple endpoint determination. This feature is particularly valuable when dealing with a fastidious, trypsin-dependent virus such as PEDV where CPE-based endpoints may not be obvious or may be confused with trypsin-induced CPE in the cell monolayer. Although neutralizing antibodies present in the serum would not be expected to provide direct protection from a strictly enteric infection such as PEDV, our data suggest a correlation between detectable neutralizing antibody levels in the serum and those present in milk and colostrum of previously exposed or vaccinated sows.

Some correlation between PEDV neutralization results and ELISA results exists as described in the literature. One study performed a comparative analysis between a whole-virus antigen ELISA and a serum neutralization test for the serodiagnosis of PEDV [21]. The presence of antibodies was confirmed by each test, and an overall testing agreement of $84.2 \%$ was demonstrated using 1024 field serum samples. Furthermore, a pairwise correlation was performed that showed corrected cutoff values between the ELISA OD and SN titers having an R value of 0.837 , indicating that the CPE-based neutralization test had roughly the same reliability as the ELISA test [21].

Newer technologies such as the FMIA are useful for the detection of antibodies against multiple antigens simultaneously for surveillance purposes. FMIA are bead based assays for simultaneous high throughput detection of antibodies to multiple antigens. The FMIA differs from the ELISA since it involves a fluid incubation step with "beads suspended in solution, which allows for higher surface area exposure in 3 dimensions" [30]. Therefore, there is a shorter diffusion path to antibody binding sites on the antigen coated beads resulting in rapid reaction times. Instead of a method using an enzymatic reaction such as with the ELISA, the FMIA detection is with laser technology, which results in a shorter detection time. This PEDV antigen specific bead set can be "mixed" with additional coated beads to other antigens, such as SIV, PCV2, PRRSV or other pathogens, for simultaneous detection of antibodies to these antigens. In addition, an FMIA could be developed for differentiation of wild-type infected vs vaccinated animals (DIVA) if proteins used in the vaccine were different from those produced in a wild-type infection.

Individual kinetic serum IgG and IgM levels were measured by FMIA in experimentally infected animals over time. The appearance of the IgM subclass is considered an immunological parameter of early infection and generally appears prior to the appearance of IgG, and this was confirmed in our study. This was in contrast to the data of Woo et al. [36], which was unable to detect IgM antibodies using their NP-based indirect ELISA. IgG antibodies may be more easily detected as they are characterized by higher antigen affinity but lower avidity than IgM [37]. Further understanding of various antibody profiles will provide important information on the ability of vaccines to stimulate a protective immune response.

\section{Conclusions}

These well-validated NA PEDV iELISA, bELISA, FMIA and FFN assays are useful for a range of serological investigations. They can serve as a complement to nucleic acid detection and determine the PEDV status of asymptomatic individuals for cost-effective tools in management strategies and monitoring virus exposure within the herd. The FMIA will be useful for isotyping the antibody responses and in multiplexing for determining exposure to multiple pathogens simultaneously. In 
addition, the FFN is useful for determining whether the antibodies measured are providing a biological function of blocking virus infectivity. Work is ongoing to further validate these assays on other sample matrices such as milk and colostrum for measuring passive transfer of antibodies and oral fluids for pen-based surveillance.

\section{Abbreviations}

PEDV: Porcine epidemic diarrhea virus; IFA: Immunofluorescent assay; iELISA: Indirect enzyme linked immunosorbent assay; bELISA: Blocking enzyme linked immunosorbent assay; FMIA: Fluorescent microsphere immunoassay; FFN: Fluorescent Focus Neutralization; ORF: Open reading frame; UTR: Untranslated region; NP: Nucleoprotein; S: Spike; E: Envelope; mAb: Monoclonal antibody; ROC: Receiver operator characteristic; TGEV: Transmissible gastroenteritis virus; PRCV: Porcine respiratory coronavirus; NA: North American; CPE: Cytopathic effect; DPI: Days post-infection; ADRDL: Animal Disease Research and Diagnostic Laboratory; RT-PCR: Reverse transcriptase polymerase chain reaction; OD: Optical density; IPTG: Isopropyl $\beta$-D-1-thiogalactopyranoside; SDS-PAGE: Sodium dodecyl sulfate-polyacrylamide gel electrophoresis; IACUC: Institutional Animal Care and Use Committee; HAT medium: Hypoxanthine-aminopterin-thymidine medium; DMSO: Dimethyl sulfoxide; BSA: Bovine serum albumin; MEM: Modified Eagles Medium; FBS: Fetal bovine serum; NVSL: National Veterinary Services Laboratories; MOl: Multiplicity of infection; TPCK: L-1-Tosylamide-2-phenylethyl chloromethyl ketone; FITC: Fluorescein isothiocyanate; ACB: Antigen coating buffer; SMD: Sample milk diluent; HRP: Horseradish peroxidase; TMB: 3,3',5,5'- tetramethylbenzidine; PI: Percent inhibition; MFI: Median fluorescent intensity; SIV: Swine influenza virus; PCV-2: Porcine circovirus type 2; PRRSV: Porcine reproductive and respiratory syndrome virus,

\section{Competing interests}

The authors declare that they have no competing interests.

\section{Authors' contributions}

FO: Conducted ELISA and FMIA development/validation, statistical analysis and co-wrote paper. XL: Conducted ELISA and FMIA development/validation. AS: Assisted with sample acquisition, assay development and study design. TC: Assisted with sample acquisition and study design. JN: Conducted virus neutralization assay development and testing. JCH: Assisted with study design and co-wrote paper. EAN: Developed study concept and design, edited paper. SL: Directed assay development and validation, co-wrote paper. All authors read and approved the final manuscript.

\section{Acknowledgements}

Funding for this work was provided by the South Dakota Agricultural Experiment Station, the South Dakota Animal Disease Research and Diagnostic Laboratory and the National Pork Board through grants 13-263 and 14-038. The authors thank Dr. Sabrina Swenson and Melinda JenkinsMoore of the National Veterinary Services Laboratories for providing the cell culture adapted PEDV-CO isolate and Dr. Richard Hesse of the Kansas State University Veterinary Diagnostic Laboratory for providing serum samples from PEDV challenge studies. The authors also thank numerous swine producers and practitioners for providing field samples and herd history information.

\section{Author details}

${ }^{1}$ Veterinary \& Biomedical Sciences Department, South Dakota State University, Brookings, SD, USA. ${ }^{2}$ National Research Center, Giza, Egypt.

Received: 27 April 2015 Accepted: 20 July 2015

Published online: 01 August 2015

\section{References}

1. Paudel S, Park JE, Jang H, Hyun BH, Yang DG, Shin HJ. Evaluation of antibody response of killed and live vaccines against porcine epidemic diarrhea virus in a field study. Vet Quart. 2014;34:194-200.

2. Debouck P, Pensaert M. Experimental infection of pigs with a new porcine enteric coronavirus, CV 777. Am J Vet Res. 1980;41(2):219-23.
3. Stevenson GW, Hoang H, Schwartz KJ, Burrough ER, Sun D, Madson D, et al. Emergence of Porcine epidemic diarrhea virus in the United States: clinical signs, lesions, and viral genomic sequences. J Vet Diagn Invest. 2013;25:649-54.

4. Adams MJ, Carstens EB. Ratification vote on taxonomic proposals to the International Committee on Taxonomy of Viruses. Arch Virol. 2012;157:1411-22.

5. Li Z, Chen F, Yuan Y, Zeng X, Wei Z, Zhu L, et al. Sequence and phylogenetic analysis of nucleocapsid genes of porcine epidemic diarrhea virus (PEDV) strains in China. Arch Virol. 2013;158:1267-73.

6. Rodak L, Valıcek L, Smıd B, Nevorankova Z. An ELISA optimized for porcine epidemic diarrhoea virus detection in faeces. Vet Microbiol. 2005;105:9-17.

7. Lin C-M, Gao X, Oka T, Vlasova AN, Esseili M, Wang Q, et al. Antigenic Relationships among Porcine Epidemic Diarrhea Virus and Transmissible Gastroenteritis Virus Strains. J Virol. 2015;89(6):3332-42.

8. van Boheemen S, de Graaf M, Lauber C, Bestebroer TM, Stalin Raj V, Moh Zaki A, et al. Genomic characterization of a newly discovered coronavirus associated with acute respiratory distress syndrome in humans. mBio. 2012;3(6):e00473-12. doi:10.1128/mBio.00473-12.

9. Baric RS, Fu K, Schaad MC, Stohlman SA. Establishing a genetic recombination map for murine coronavirus strain A59 complementation groups. Virology. 1990;177:646-56.

10. Huang Y-W, Dickerman AW, Piñeyro P, Li L, Fang L, Kiehne R, et al. Origin, evolution, and genotyping of emergent porcine epidemic diarrhea virus strains in the United States. mBio. 2013; 4(5) doi:10.1128/mBio.00737-13.

11. Marthaler D, Bruner L, Collins J, Rossow K. Third strain of porcine epidemic diarrhea virus, United States. Emerg Infect Dis. 2014; 20(12). doi:10.3201/ eid2012.140908.

12. Saif LJ. Coronavirus immunogens. Vet Microbiol. 1993;37:285-97.

13. Sturman LS, Holmes KV. The molecular biology of coronaviruses. Adv Virus Res. 1983;28:35-122

14. Pensaert MB, de Bouck P. A new coronavirus-like particle associated with diarrhea in swine. Arch Virol. 1978;58:243-7.

15. Hofmann M, Wyler R. Enzyme-linked immunosorbent assay for the detection of porcine epidemic diarrhea coronavirus antibodies in swine sera. Vet Microbiol. 1990;21:263-73.

16. Knuchel M, Ackermann M, Muller HK, Kihm U. An ELISA for detection of antibodies against porcine epidemic diarrhoea virus (PEDV) based on the specific solubility of the viral surface glycoprotein. Vet Micro. 1992;32:117-34.

17. Carvajal A, Lanza I, Diego R, Rubio P, Carmenes P. Evaluation of a blocking ELISA using monoclonal antibodies for the detection of porcine epidemic diarrhea virus and its antibodies. J Vet Diag Invest. 1995;7:60-4.

18. Ren X, Suo S, Jang Y-S. Development of a porcine epidemic diarrhea virus M protein-based ELISA for virus detection. Biotechnol Lett. 2011;33:215-20.

19. Hou X-L, Yu L-Y, Liu J. Development and evaluation of enzyme-linked immunosorbent assay based on recombinant nucleocapsid protein for detection of porcine epidemic diarrhea (PEDV) antibodies. Vet Microbiol. 2007;123:86-92.

20. Gerber PF, Gong Q, Huang Y-W, Wang C, Holtkamp D, Opriessnig T. Detection of antibodies against porcine epidemic diarrhea virus in serum and colostrum by indirect ELISA. Vet J. 2014;202:33-6.

21. Oh JS, Song DS, Yang JS, Song JY, Moon HJ, Kim TY, et al. Comparison of an enzyme-linked immunosorbent assay with serum neutralization test for serodiagnosis of porcine epidemic diarrhea virus infection. J Vet Sci. 2005:6:349-52

22. Debouck P, Pensaert M. Porcine epidemic diarrhea: Kinetics of actively and passively acquired serum antibodies and the effect of reinfection. Proc Int Pig Vet Soc Congr. 1984;8:53.

23. Lawson S, Lunney J, Zuckermann F, Osorio F, Nelson E, Welbon C, et al. Development of an 8-plex Luminex assay to detect swine cytokines for vaccine development: Assessment of immunity after porcine reproductive and respiratory syndrome virus (PRRSV) vaccination. Vaccine. 2010;28:5383-91.

24. Langenhorst R, Lawson S, Kittawornrat A, Zimmerman J, Sun Z, Li Y, et al. Development of a fluorescent microsphere immunoassay for detection of antibodies against PRRSV using oral fluid samples as an alternative to serum-based assays. Clin and Vacc Imm. 2012;19:180-9.

25. Jacobson $\mathrm{RH}$. Validation of serological assays for diagnosis of infectious diseases. Rev Sci Tech Of Int Epizoot. 1998;17:469-526. 
26. Nelson EA, Christopher-Hennings J, Drew T, Wensvoort G, Collins JE, Benfield D. Differentiation of U.S. and European Isolates of Porcine Reproductive and Respiratory Syndrome Virus by Monoclonal Antibodies. J Clin Micro. 1993;31:3184-9.

27. Galfre G, Howe SC, Milstein C, Butcher GW, Howard JC. Antibodies to major histocompatibility antigens produced by hybrid cell lines. Nature (London). 1977;266:550-2.

28. Landis JR, Koch GG. The measurement of observer agreement for categorical data. Biometrics. 1977;33:159-74.

29. Abdo J, Kristersson T, Seitzer U, Renneker S, Merza M, Ahmed J. Development and laboratory evaluation of a lateral flow device (LFD) for the serodiagnosis of Theileria annulata infection. Parasitol Res. 2010:107:1241-8

30. Christopher-Hennings J, Araujo KPC, Carlos CJH, Fang Y, Lawson S, Nelson EA, et al. Opportunities for bead-based multiplex assays in veterinary diagnostic laboratories. J Vet Diagn Invest. 2013;25:671-91.

31. Vlasova AN, Marthaler D, Wang Q, Culhane MR, Rossow KD, Rovira A. Distinct characteristics and complex evolution of PEDV Strains, North America, May 2013-February 2014. Emerg Infect Dis. 2014;20:1620-8.

32. Jung K, Wang Q, Scheuer KA, Lu Z, Zhang Y, Saif L. Pathology of US Porcine Epidemic Diarrhea Virus Strain PC21A in Gnotobiotic Pigs. Emerg Infect Dis. 2014:20:662-5

33. Horzinek MC, Lutz H, Pedersen N. Antigenic relationships among homologous structural nucleotide sequences of porcine, feline and canine coronaviruses. Infect Immun. 1982;37:1148-55.

34. Yaling Z, Ederveen J, Egberink H, Pensaert MB, Horzinek MC. Porcine epidemic diarrhea virus (CV777) and feline infectious peritonitis virus (FIPV) are antigenically related. Arch Virol. 1988:102:37-71.

35. Schrijver RS, Kramps JA. Critical factors affecting the diagnostic reliability of enzyme-linked immunosorbent assay formats. Rev Sci Tech Of Int Epizoot. 1998;17:550-61.

36. Woo PC, Lau SK, Wong BH, Chan KH, Chu CM, Tsoi HW, et al. Longitudinal profile of immunoglobulin $\mathrm{G}(\mathrm{lgG})$, IgM, and $\lg \mathrm{A}$ antibodies against the severe acute respiratory syndrome (SARS) coronavirus nucleocapsid protein in patients with pneumonia due to the SARS coronavirus. Clin Diagn Lab Immunol. 2004;11:665-8.

37. Murphy K, Travers P, Walport M. The Distribution and Functions of Immunoglobulin Classes. In: Janeway's Immunobiology. 7th ed. New York: Garland Science; 2008. p. 400-1.

\section{Submit your next manuscript to BioMed Central and take full advantage of:}

- Convenient online submission

- Thorough peer review

- No space constraints or color figure charges

- Immediate publication on acceptance

- Inclusion in PubMed, CAS, Scopus and Google Scholar

- Research which is freely available for redistribution 